\title{
ANALYSIS ON THE CAUSE OF VALLEY WIDTH SHRINKAGE OF AN ULTRA-HIGH ARCH DAM AND ITS INFLUENCE ON DAM SAFETY RISK
}

\author{
Fan Qixiang ${ }^{1} \quad$ Liu Youzhi $^{2} \quad$ Zhang Guoxin ${ }^{3}$ Cheng Heng ${ }^{4} \quad$ Xiang \\ Jianfang $^{5}$ Zhou Qiujing ${ }^{6}$ \\ ${ }^{1}$ China Three Gorges Corporation ,Beijing China \\ ${ }^{2 \sim 6}$ Department of Structure and Materials, China Institute of Water Resources and Hydropower \\ Research, Beijing, China \\ 1Fan qixiang@Ctgpc.com.cn, ${ }^{2} 371109339 @ q q . c o m,{ }^{3}$ gx-zhang@iwhr.com, \\ 76499941@qq.com, ),,1160415109@qq.com, ${ }^{6}$ Zhouqj@iwhr.com
}

\begin{abstract}
Key words: ultra-high arch dam; valley width shrinkage; dam foundation seepage; rock mass creep; temperature field

Abstract: To better understand the phenomenon of valley width shrinkage after the impoundment of an ultra-high arch dam, the cause and mechanism of the narrowing of valley width on both sides of the high arch dam during the impoundment stage are studied and analyzed. The effect of reservoir water pressure and bedrock temperature drop on valley width narrowing is found to be limited; after impounding, the change in the seepage field of the bedrock mass disequilibrates the pre-impounding natural stress balance of the intra- and inter-laminar dislocation band. The triggering of creep deformation of the rock mass is thereby a major cause of valley width shrink. The results of actual monitoring and feedback simulation analysis also confirm this deduction. Ultimately, the effect of valley width shrink on the overall displacement and stress of the dam is further analyzed. Suggestions are proposed for the strengthening of tracking observation analysis in the later stage, dam area expansion, and the observation range of reservoir deformation.
\end{abstract}

\section{Introduction}

Super high dam, those taller than $200 \mathrm{~m}$, are commonly built in alpine and gorge regions. Both sides of the abutment slope are high and steep. The rock mass underneath the dam and the reservoir area may be subject to high stress due to the geological structure and the self-weight, but the rock slope is generally in a stable state in natural conditions. As the original state stress is unbalanced by the excavation of the dam foundation and the slope cover in the dam site, the rock mass frequently shows clear unloading relaxation and shrinkage deformation towards the valley. During the first filling of the dam, the reservoir basin displays evident settlement deformation under the effect of water pressure; it also causes the rock mass above the water surface on both sides to undergo deformation towards the center of the valley. In addition, the change in the seepage field of the dam bedrock mass after the first filling of the dam will further affect the stress balance of the rock mass on both abutments, resulting in a valley-narrowing deformation trend, that is, both abutments shrink towards the center of the valley. These phenomena have been observed in arch dam construction projects in China and internationally, in some cases even compromising the project safety.

Beauregard arch dam (132 m high, concrete arch-gravity dam, completed in 1960) is a typical case of a damaged dam structure caused by valley width deformation. After completion of the dam, due to the poor geological conditions of the slope rock mass on the left bank abutment, the integral slipping after impoundment of the left bank structural plane caused substantial valley width shrinkage on both banks of the dam in a short time. The total deformation reached $45 \mathrm{~mm}$ in four months, resulting in the center of the crest moving upstream; the left abutment shifted towards the right bank, and the downstream face of the dam appeared to crack. Under these conditions the dam was found unable to safely meet the demands of normal operation (Barla $G$ et al. 2010). Zeuzier arch dam, Nalps arch dam, and Santa Maria arch dam, all located in Switzerland, all displayed 
valley width deformation caused by changes in the foundation stress conditions after the first filling of the reservoir (Giovanni Lomdi \& Lombardi SA 1993).

In China, Lijiaxia arch dam (155 m high), Xiaowan arch dam (294.5 m high), Xiluodu arch dam (285.5 m high), and Jinping-I arch dam (305 m high) (Develay D et al. 1997 , Jie Yang et al 2005, Qiang Yang et al. 2015, You-zhi Liu et al. 2014, respectively) also showed valley width shrinkage of varying degrees during the construction period and impoundment operation stage. Due to differences in geological conditions, the magnitude of valley width shrinkage of arch dams varies, and the effect on the structural safety of the dam varies as well.

The deformation of valleys and dams is often the result of the combined effects of various factors, and its causes and mechanisms can be very complex. At present, there are relatively few studies on the cause of valley width shrinkage deformation of high arch dams during construction and impoundment; the current understanding of the valley deformation mechanism is somewhat insufficient. It is necessary to include the on-site monitoring data of typical arch dams to thoroughly study this mechanism, especially during the early-stage impoundment of super high arch dams. The effective definition and assessment of the safety risks of the valley-width shrinkage deformation mechanism will help understanding the true physical behavior of the dam. The provision of scientific support in this area will help to ensure the safe operation of projects. Likewise, relevant research results can also provide a reference for similar projects that are under construction or imminent construction.

This paper presents the analysis of the valley shrinkage deformation and the numerical verification of a typical super high arch dam.

Analysis of the mechanism and influencing factors of valley shrinkage deformation of super high arch dams

\section{General geological site conditions and analysis of monitoring results}

The dam in the current study is a concrete double-curvature arch dam. Its maximum height is 285.5 $\mathrm{m}$, and the crest elevation is at $610 \mathrm{~m}$. The bedrock mass on both abutments of the dam is a layered structure of basalt. The intra- and inter-laminar disturbed belts are well jointed, and a typical section is shown in Figure 1, and the material parameters are shown in Table 1.

Table 1. Material parameter table

\begin{tabular}{|c|c|c|c|c|c|c|c|c|c|}
\hline \multirow{2}{*}{$\begin{array}{c}\text { Material } \\
\text { I type } \\
\text { rock }\end{array}$} & \multirow{2}{*}{$\begin{array}{c}\begin{array}{r}\text { Density } \\
\left(\mathbf{k g} / \mathbf{m}^{3}\right)\end{array} \\
2750\end{array}$} & \multicolumn{2}{|c|}{$\begin{array}{c}\text { Modulus of } \\
\text { elasticity(GPa) } \\
\text { Horizontal/vetical }\end{array}$} & \multirow{2}{*}{$\begin{array}{c}\begin{array}{c}\text { Poisson's } \\
\text { ratio }\end{array} \\
0.18\end{array}$} & \multirow{2}{*}{$\begin{array}{c}\begin{array}{c}\text { C. of linear } \\
\text { expansion } \\
\left(\times 1^{-6}\right)\end{array} \\
39\end{array}$} & \multirow{2}{*}{$\begin{array}{c}\begin{array}{c}\text { Compressive } \\
\text { strength (MPa) }\end{array} \\
15\end{array}$} & \multirow{2}{*}{$\begin{array}{c}\begin{array}{c}\text { Tensile } \\
\text { strength } \\
\text { (MPa) }\end{array} \\
1.5 \\
\end{array}$} & \multirow{2}{*}{$\begin{array}{c}\begin{array}{c}\text { Cohesion } \\
\text { (MPa) }\end{array} \\
2.5\end{array}$} & \multirow{2}{*}{$\begin{array}{c}\begin{array}{c}\text { Friction } \\
\text { angle }\left({ }^{\circ}\right)\end{array} \\
53.47\end{array}$} \\
\hline & & $33-50$ & $33-50$ & & & & & & \\
\hline $\begin{array}{l}\text { II type } \\
\text { rock }\end{array}$ & 2750 & $22-30$ & $16-22$ & 0.20 & 39 & 15 & 1.5 & 2.5 & 53.47 \\
\hline $\begin{array}{l}\text { III1 type } \\
\text { rock }\end{array}$ & 2750 & $14-20$ & $13-16$ & 0.22 & 39 & 10 & 1.0 & 2.2 & 50.66 \\
\hline $\begin{array}{l}\text { III2 type } \\
\text { rock }\end{array}$ & 2750 & $7-9$ & $5-8$ & 0.23 & 39 & 10 & 1.0 & 1.4 & 50.19 \\
\hline $\begin{array}{l}\text { IV } 1 \text { type } \\
\text { rock }\end{array}$ & 2750 & $4-5$ & $4-5$ & 0.25 & 39 & 5 & 0.5 & 1.0 & 45.57 \\
\hline $\begin{array}{l}\text { IV2 type } \\
\text { rock }\end{array}$ & 2750 & $1-2.6$ & $\begin{array}{c}0.7- \\
1.2 \\
\end{array}$ & 0.28 & 39 & 5 & 0.5 & 0.5 & 35.00 \\
\hline $\begin{array}{c}\text { Weak } \\
\text { interlayer }\end{array}$ & 2750 & $0.7-1.1$ & $\begin{array}{c}0.4- \\
0.5 \\
\end{array}$ & 0.32 & 39 & 5 & 0.5 & 0.5 & 35.00 \\
\hline Concrete & 2635 & 25 & 25 & 0.17 & 6.3 & 27.4 & 2.2 & 3.0 & 58.30 \\
\hline
\end{tabular}


Impoundment of the dam began at the end of 2012 and reached its normal impoundment level in October 2014.At present, the normal impoundment has been operated for three years. There are eight sets of valley-width monitoring sites arranged for the dam, four upstream and four downstream of the dam, each with measurement points on both sides of the valley. The monitoring deployment plan is shown in Figure 2. The measurement has been regular from the beginning of impoundment. As of October 2016, the cumulative valley width shrinkage ranges from 54.86 to $72.73 \mathrm{~mm}$; the cumulative valley width shrinkage after filling ranges from 48.41 to $68.49 \mathrm{~mm}$, with the maximum shrinkage reading at VDR03 VDL03 (elevation $722 \mathrm{~m}$ ), and there is no obvious relevance with height and distance between the centre of the dam and the abutments. The valley width shrinkage increases uniformly throughout the entire course of the filling regardless of the drop in water level. The correlation between valley-width shrinkage and water level change due to impoundment is not evident; the valley width shrinkage upstream and downstream of the dam are the same. A graph comparing changes in valley width and water level is shown in Figure 3. The valley width was also reflected in the monitoring data of the dam chord-length, and the maximum chord-length reduction has reached $50 \mathrm{~mm}$, as shown in Figure 4, In which TPL-1 TPR-1, TP41 TP28-1, TP5-1 TP25-1 and TP24-1 TP6-1 represent the chord-length between two fixed point in left and right, \#4 and \#28, \#5 and \#25, \#24 and \#6 respectively.

To thoroughly understand whether the valley-width narrowing is the result of a superficial deformation or an integrated rock mass shrink deformation, new valley-width monitoring sites were established at elevation of $559 \mathrm{~m}$ in March 2014; the valley-width monitoring line extended to both ends of the ADR20 and ADL20 drainage holes, which were excavated during construction and are presented as VDR08-01 VDR08-03 and VDL08-01 VDL08-03 in Fig 2. The cross-strait cave line is approximately at level $140 \mathrm{~m}$. The monitoring survey revealed that the position of the drainage entrance at both ends has cumulatively shrunk by $27.69 \mathrm{~mm}$ in the past two years. The monitoring line in the drainage interior of the right bank has extended by $0.28 \mathrm{~mm}$, and the one in the left bank has extended by $1.34 \mathrm{~mm}$, which indicates that the displacement of the rock mass near the dam area is relatively small. The valley width shrinkage of both banks is more likely to be caused by largescale regional deformation. Figure 5 shows the elevation of the valley width measuring points upstream and downstream of the dam, revealing the overall translational shift trend on both abutments. In addition, the monitoring data on the dam at different levels show an increasing trend in the overall elevation of the dam after the normal impoundment of the dam was reached in October 2014, as shown in Figure 6 in which EM1-1 to EM1-31 means the location from \#1 to \#31.

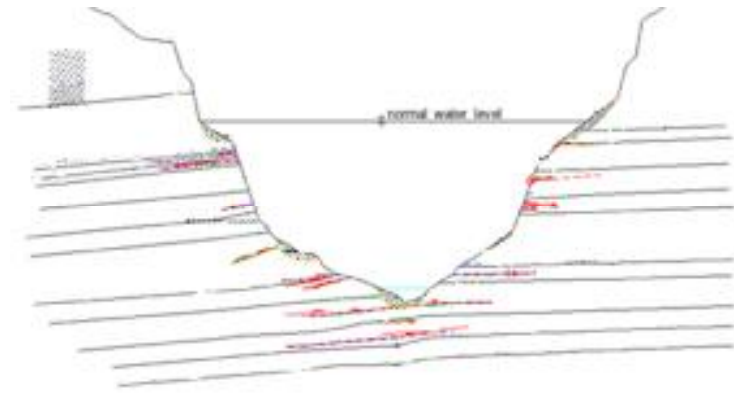

Fig 1. Typical cross-section profile of the dam foundation(the continuous lines represent Interlayer and the red lines represent chasm)

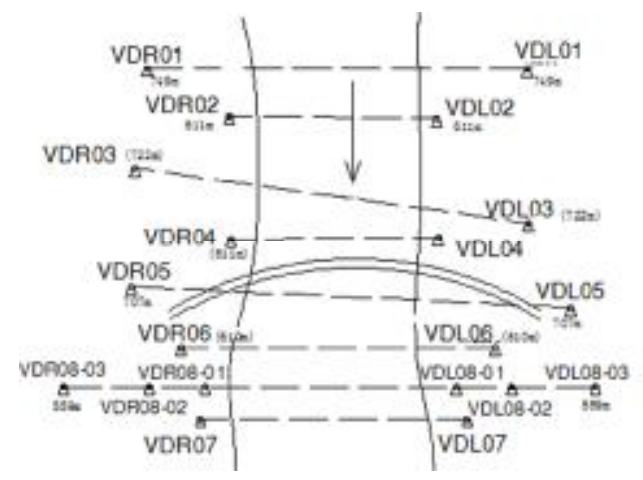

Fig 2. Planar view of valley-width monitoring lines 


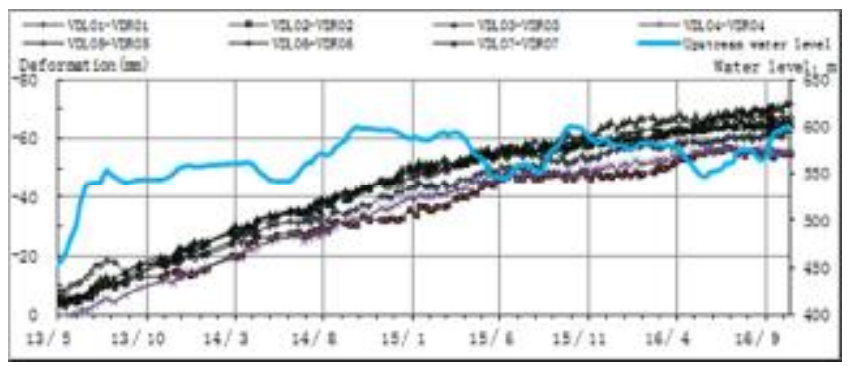

Fig 3. Measured valley width variation curve

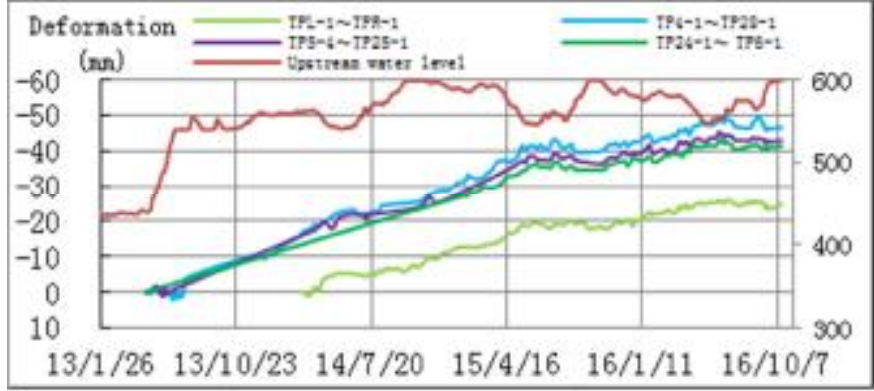

Fig 4. Chord-length variation curves at different locations

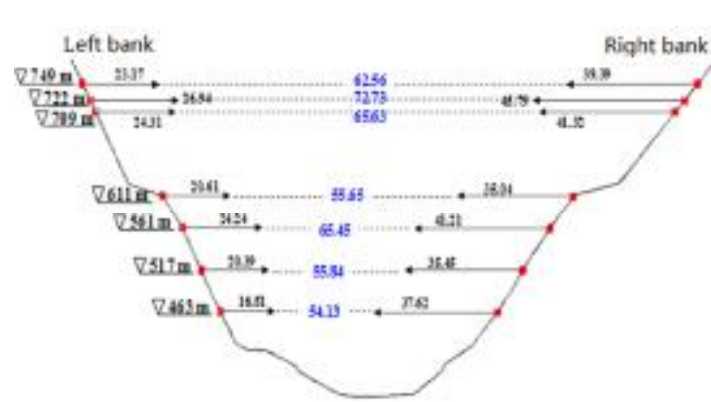

Fig 5. Cross valley width shrinkage diagram

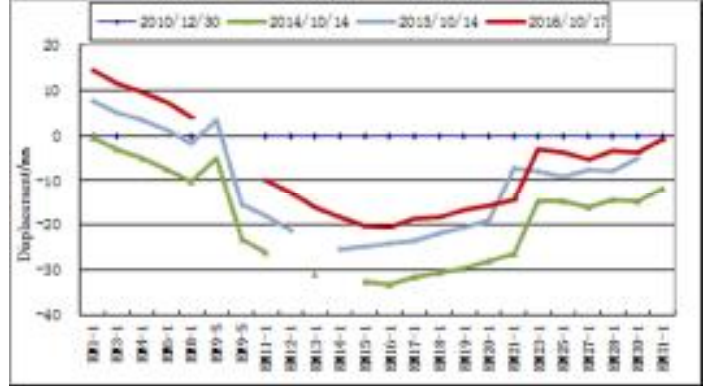

Fig 6. Vertical displacement diagram of the corridor in $334 \mathrm{~m}$ high

\section{Influencing factors and mechanism analysis}

The monitoring data on the valley width and chord length shown that the reduction in valley width and chord length cannot be correlated with the water level and the time of the impoundment. However, the valley width and chord length do show a reduction in inclination since the beginning of impoundment, and the tendency gradually approaches convergence after 2015. The deformations also exceeds the conventionally expected amounts, indicating that in addition to conventional influential factors, such as unloading relaxation, this behavior may also be associated with the special hydrogeological conditions of the project. The impact of the latter plays a decisive role. The continued study that follow-up in recent years has found that the factors affecting the valley-width shrinkage deformation of the project mainly include basin settlement, thermal contraction of bedrock, and rock mass creep deformation of the dam foundation under couplied of seepage force and rock stress.

\section{Basin settlement}

The monitoring data of the reservoir area clearly indicate that upstream basin settlement occurred from the start of impoundment till the moment when the normal impoundment level of the dam was reached. The average sedimentation value upstream is approximately $20 \mathrm{~mm}$; obviously the basin water pressure after impoundment is the primary factor causing deformation of the basin. The basin 
settlement causes shrinkage deformation of the upper rock mass, leading to valley-width shrinkage deformation; therefore, basin settlement is one of the factors leading to valley width shrinkage.

\section{Effect of bedrock temperature decrease}

Under natural river conditions, the temperature of the bedrock mass of the riverbed is affected by the temperature change, which is commonly believed to follow a seasonal cycle. However, the impoundment of the dam causes low-temperature water to accumulate in the bottom of the reservoir, with temperatures similar to those of the river water in the coldest month. This stored water can affect the rock foundation temperature to a certain extent, causing shrinkage of the lower rock foundation as temperature decreases; it may also cause valley-width shrinkage deformation of the upper rock mass in the reservoir area, and therefore is regarded as one of the factors contributing to valley width shrinkage. In addition, the temperature and seepage fields may generate coupled effectsmay result in bedrock deformation. Those coupled effect need to be considered and thoroughly studied.

\section{Creep effect caused by the coupled seepage and rock stresses}

It takes many years to form a stable seepage after the first impoundment after completion of the dam,. In this process, the original natural seepage field of the dam bedrock mass changes, and the rock mass mechanical properties in the intra- and inter-laminar disturbed belts may be weakened to a certain extent. The weakening of rock mass parameters will unbalance the original balance of stresses in the internal rock mass, resulting in the creep effect of some structural planes in the intraand inter-laminar dislocation band; the external representation is the integral slippage along the structural plane. The complex characteristics of the layered rock mass of this project and the dry rock mass of both banks before the impoundment make the weakened mechanical property a more prominent characteristic of the rock mass, after the reservoir flow field is changed. The slow creep deformation caused by this effect was captured by in the the results of safety monitoring data from the project site and it is believed, based on analysis, that this effect is the primary factor of causing large-scale valley width shrinkage in this project.

\section{Deformation mechanism feedback analysis and numerical verification}

To examine the influential factors causing valley-width shrinkage deformation in this project, a feedback analysis was conducted based on the on-site safety monitoring data, For this purpose, a simulation computing model that contains regions upstream and downstream of the dam within a range of $20 \mathrm{~km}$, with the mountain included, was constructed. Figure 7 shows a typical crosssection of the valley in the dam area, and the intra- and inter-laminar dislocation band is simulated in the model. What's more, the soft we use in the paper is SAPTIS by element of eight-node hexahedron.

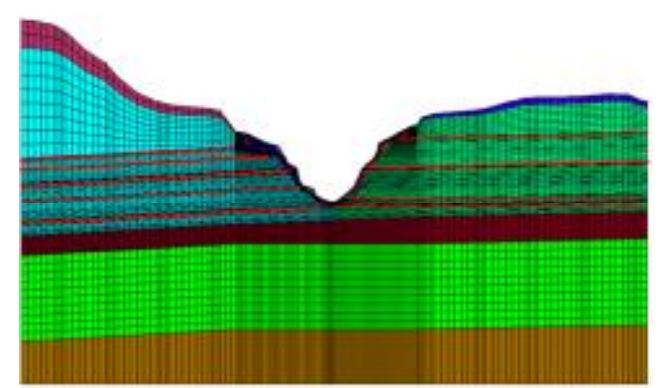

Figure 7. Cross section of finite element

mesh

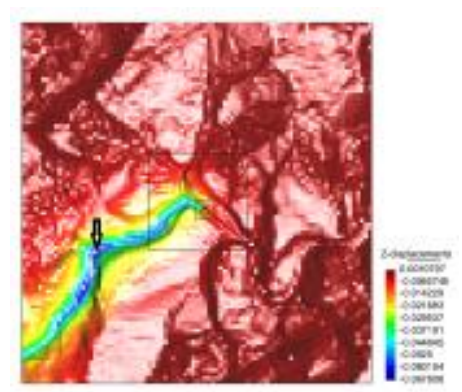

Fig 8. Schematic diagram of vertical displacements due to sedimentation 


\section{Reservoir basin sedimentation factors}

Based on the inversion analysis of the elastic modulus of the dam bedrock, the influence of the reservoir basin sedimentation was studied and analyzed. As shown in Figures 8 and 9, the primary principles are as follows: the normal impoundment below elevation $600 \mathrm{~m}$ shows an expansion trend, whereas above that elevation, narrowing occurs above the water level. The higher the elevation, the greater the narrowing. The maximum shrinkage $(5.4 \mathrm{~mm})$ occurred at the valley width measuring point VDL01 (749 m elevation). The valley-width shrinkage above the water level is consistent with the actual measured values, but the deformation below water level is opposite to the measured values. Therefore, the reservoir basin settlement is not the primary factor affecting the valley width shrinkage. The max deformation occurs in the upstream which is shown by the arrow in Fig 8.

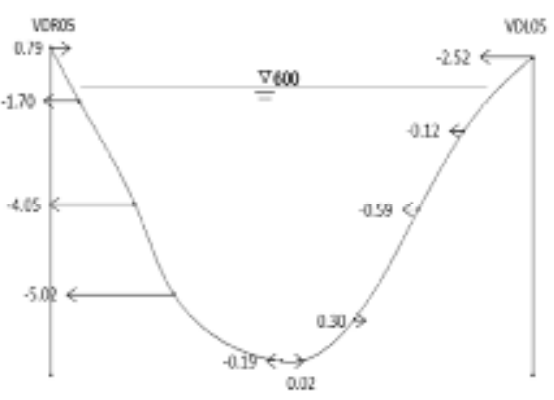

(a) deformation in vetical

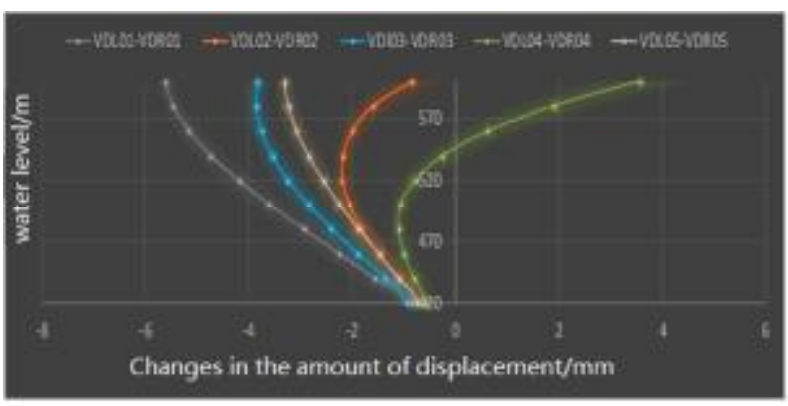

(b) deformation varies with elevation changes

Fig9. Diagram of maximum settlement upstream of the reservoir basin with the water level at $600 \mathrm{~m}$

\section{Coupled temperature and seepage factors}

The average ground temperature of the lower bedrock ( $50 \mathrm{~m}$ below the foundation surface) of the dam site prior to the project impoundment can reach approximately $35-40{ }^{\circ} \mathrm{C}$. The water temperature of the lower bedrock is lower (approximately $15^{\circ} \mathrm{C}$ ) after reservoir impoundment. Assuming that low-temperature water infiltrates into the deep rock mass under the action of seepage force, which leads to a large-scale temperature drop-induced contraction in the high-temperature region of the dam foundation, valley width shrink may occur as a result. The coupled temperature and seepage effect was analyzed by taking the extreme temperature drop of the rock foundation in order to find out the relationship between temperature drop and valley shrinkage. The result showed that the valley width shrinks $35-40 \mathrm{~mm}$, based on an assumed average temperature drop of the low bedrock of approximately $20^{\circ} \mathrm{C}$, while the reservoir bottom in the dam area settles by $40 \mathrm{~mm}$. The actual monitoring data indicated that basin sedimentation and reservoir basin water pressure are consistent with normal impoundment of the dam, and the dam bedrock mass displays upheaval deformation after a normal impoundment of $600 \mathrm{~m}$ is reached. Obviously, the assumption that the deformation effect is caused by the $20^{\circ} \mathrm{C}$ temperature drop of the bedrock does not correspond to the actual monitoring conditions, and therefore the impact of this factor can basically be ruled out. The results of this calculation are shown in Figures 10 and 11.

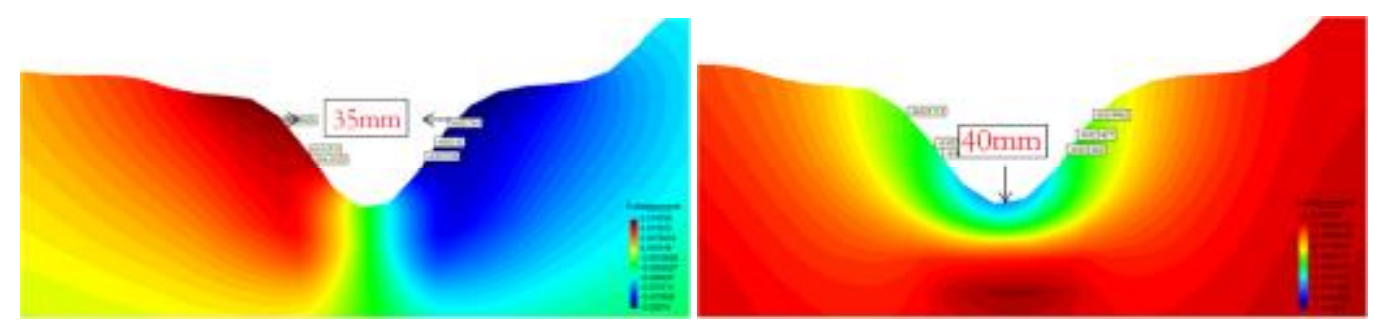

Fig 10. Cross valleyon deformation

Fig 11. Vertical deformation 


\section{Rock creep factor}

The monitoring data shown in Figure 5 indicate that the valley-width shrinkage values at different elevations are basically the same. This consistency indicates that the overall emergence of valley shrinkage deformation in this project reflected the translational deformation of the rock mass of both abutments towards the center of the valley. Combining the characteristics of the geological structure of the project, along with the gradual elevation of the water level, the water permeates the rock mass through an inter-laminar dislocation band and fissures, leading to a decrease in normal stress in the intra- and inter-laminar dislocation bands. During the transformation of the constant seepage field from the non-constant seepage field, the original stress balance of the rock mass on both abutments is unbalanced due to the creep effect of the rock mass and the softening of the material by water; the creep deformation is easily triggered along the intra- and inter-laminar dislocation bands.

A linear analysis was performed to confirm this assumption, with December 2012 set as the starting point in the simulation calculation. First, the original stress field generated by self-weight is computed, and the result serves as the initial condition to calculate the change in the seepage field that causes creep deformation of both rock masses abutments during impoundment. According to the actual impoundment and boundary conditions, the non-constant process of change of the seepage field in the reservoir area is simulated. The intra- and inter-laminar dislocation bands are simulated using the joint unit that can simulate the opening and closing of the structural plane and shear dislocation. The loads considered in the simulation include self-weight, water pressure, fissure seepage, rock mass, and creep deformation of the intra- and inter-laminar dislocation bands.

Figure 12 shows the seepage field distribution forthree typical water levels. The reservoir water level is raised with the impoundment, and the reservoir water gradually permeates the rock mass and then slowly stabilizes.

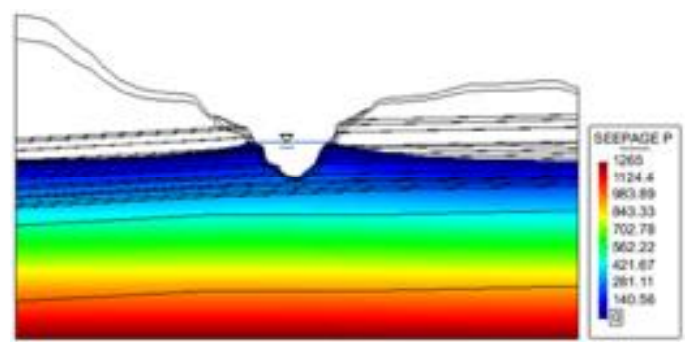

(a) Water level at $600 \mathrm{~m}$ in October 2014

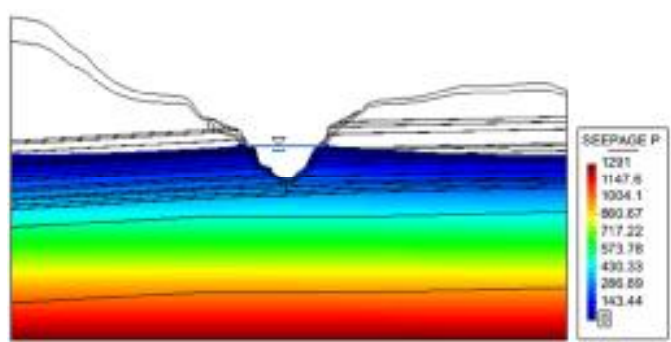

(b) Water level at $600 \mathrm{~m}$ in October 2015

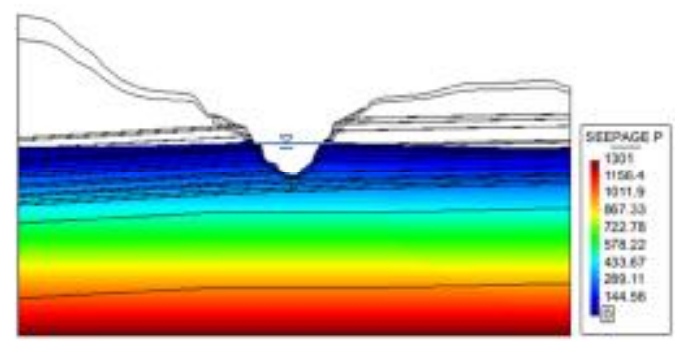

(c) Water level at $600 \mathrm{~m}$ in October 2016

Fig12. Distribution of seepage field at normal water level from 2014 to 2016 (Unit: m)

Figure 13 shows the valley-width deformation nephogram at a water level of $600 \mathrm{~m}$. The numerical simulation results and the actual valley deformation value and pattern of the bank are consistent, which is shown in the table below. The deformation of the right bank is basically twice the deformation of the left bank, and the calculated value is slightly larger than the measured value. These analysis results reveal that the valley deformation mechanism is generally due to changes in 
the hydrogeological conditions in the reservoir area (starting with non-stable seepage, continuing with stable seepage, and softening), triggering creep deformation along the intra- and inter-laminar dislocation bands.

Table 2. Deformation comparison table

\begin{tabular}{|c|c|c|c|c|}
\hline \multirow{2}{*}{ Elevation } & \multicolumn{2}{|c|}{$\begin{array}{l}\text { Deformation of the left bank towards } \\
\text { the valley center }(\mathrm{mm})\end{array}$} & \multicolumn{2}{|c|}{$\begin{array}{l}\text { Deformation of the right bank towards the } \\
\text { valley center }(\mathbf{m m})\end{array}$} \\
\hline & Calculation & Measured value & Calculation & Measured value \\
\hline $610 \mathrm{~m}$ & 26.3 & 26.9 & 38.2 & 45.7 \\
\hline $714 \mathrm{~m}$ & 27.9 & 24.3 & 40.1 & 41.3 \\
\hline $722 \mathrm{~m}$ & 28.1 & 20.6 & 39.7 & 35.1 \\
\hline
\end{tabular}

Fig 13. Valley width deformation nephogram (water level at $600 \mathrm{~m}$ )

\section{Effect of valley-width shrinkage on dam stress}

Considering the significant shrinkage of the valley width in this project, its effect on dam safety was analyzed by applying a three-dimensional finite element simulation method. The model considers the impact of conventional loads such as water pressure, temperature load and dam weight on the valley-width shrinkage, by imposing uniform loads on the left and right bedrock mass abutments. Valley-width shrinkage values of $60 \mathrm{~mm}$ and $80 \mathrm{~mm}$ were investigated, and the calculated results are assessed below:

When the valley-width shrinkage is $60 \mathrm{~mm}$, the effect is generally beneficial, improving the stress of the dam toe area; the compressive stress level of the dam toe is reduced. When the lowest water level of the dam reaches the elevation of $540 \mathrm{~m}$, disadvantageous tensile stress mainly occurs at the dam abutments on the downstream faces; at elevations above $400 \mathrm{~m}$, the maximum stress can reach approximately $1.5 \mathrm{MPa}$. When the valley width shrinkage is $80 \mathrm{~mm}$, the maximum tensile stress can reach approximately 2.0 MPa. The tensile stress will further decrease as the water level increases. When the impoundment is at a normal level, the maximum tensile stress can be controlled below 1.0 MPa, indicating that the overall stress level of the dam is still within the safe range.

Based on the intrinsic valley width shrinkage mechanism and its development trend in the current project, and considering that the monitored valley width shrinkage deformation value shows a convergent trend (although not completely convergent), the follow-up operation process should still focus on the future trend of the valley-width shrinkage deformation. Before the valley width shrinkage deformation is stable, when conditions permit, the upstream water level should be kept relatively high. 

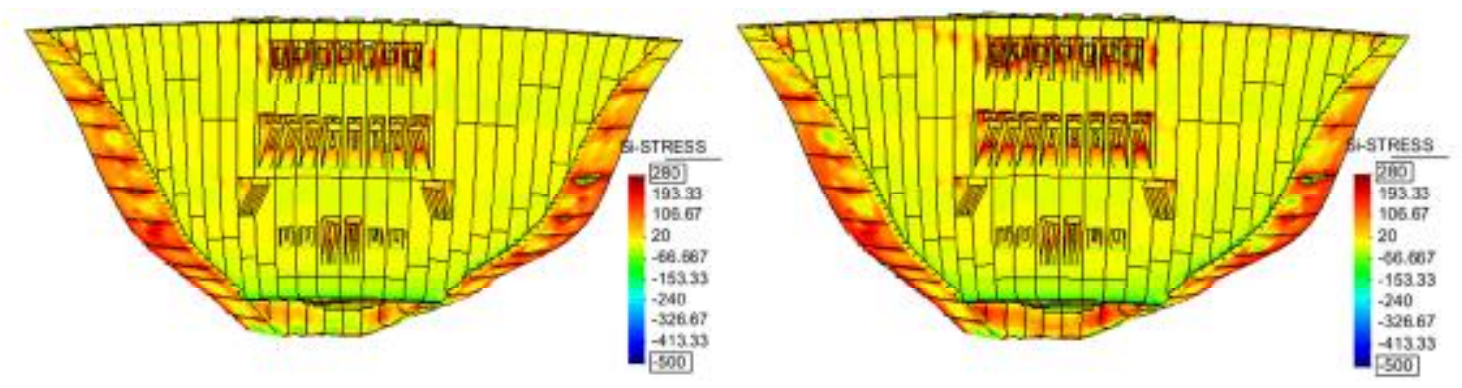

(a) Valley width shrinkage of $0 \mathrm{~mm}$, at $540 \mathrm{~m}$ (b) Valley widdh shrinkage of $0 \mathrm{~mm}$, at $600 \mathrm{~m}$
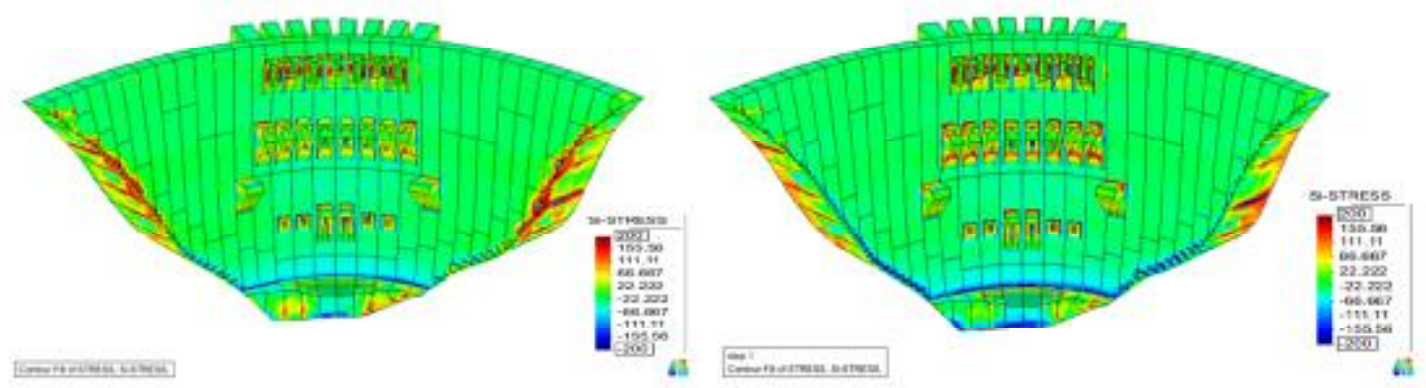

(c) Valley widlh shrinkuge ol $60 \mathrm{~m}$ m, al $540 \mathrm{~m}$ (d) Valley wideh shrinkage of $60 \mathrm{~mm}$, at 600 m
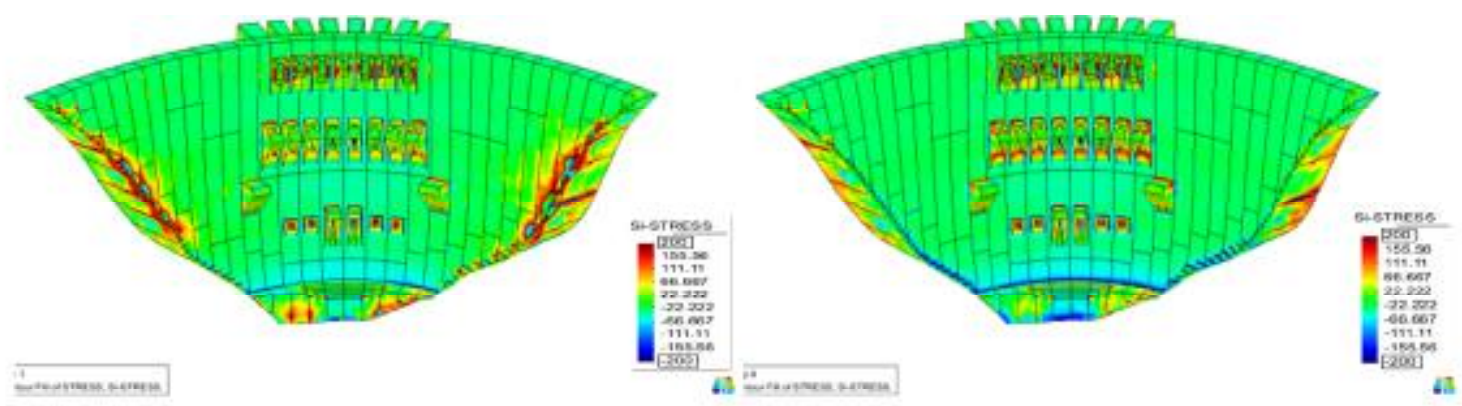

(e) Valley width shrinkage of $80 \mathrm{~mm}$, at $540 \mathrm{~m}$ (f) Valley width shrinkage of $80 \mathrm{~mm}$, at $600 \mathrm{~m}$

Figure 14. Townstream stress distribution for diferent levels of valley width shrinkáge and waler levels (Unit: $10 \mathrm{kPa}$ )

\section{Conclusions and recommendations}

The conclusions and recommendations based on the study of this project are as follows:

(1) The coupled ellects of basin sedimentation and temperature-seepage are not the main factor: leading to valley-shrinkage deformation. The ereep defonnation generaled by the changes in hydrogeological conditions of the reservoir ares is the main factor in the valloy-width shrinkage.

(2) The main negative impact of the talley width shrithage on the dam operational conditions is mainly observed in the increased stress in the arch crown beam section of the upstream region, on the downstream surface angle, and on the left and right sides of the dam abutment. $A$ fter factors such as upstream water pressure are considered, the stress level of the dam is still within an aceeptable range, which keeps the dam in a safe state.

(3) Considering that the valley shrinkage deformation of both sides of the mountain has not been completely stabilized, its impact on long-torm dam opcration salety is still in need of further tracking and assessment. 


\section{Acknowledgements}

This paper was supported by China Three Gorges Corporation research project, the Natural Science Foundation of China (No: 51779277, 51579252, 51439005), the National Key Research and Development Project of China (2016YFB0201000), the special fund(2016ZY10 、 SS0145B392016、SS0145B612017), of China Institute of Water Resources and Hydropower Research, State Key Laboratory of Simulation and Regulation of Water Cycle in River Basin.

\section{References}

[1] Barla G, Antolini F, \& Barla M (2010). Monitoring of the Beauregard landslide (Aosta Valley, Italy) using advanced and conventional techniques. Engineering Geology, Issue 116, pp 218235.

[2] Develay D, Hagen R J \& Bestagno R (1997). Design and construction of Katse Dam: Lesotho highlands water project. Civil Engineering, Volume 120, Issue 5, pp 14-29.

[3] Giovanni L, \& Lombardi SA (1993). The FES rock mass model-Part 2: Some examples. Dam Engineering, Vol III, Issue 3, pp 201-221.

[4] Jie Y, De-xiu H, \& Wen-hai G (2005). Analysis of high slope rock deformation and safety performance for left bank of Lijiaxia arch dam. Chinese Journal of Rock Mechanics and Engineering. Volume 24, Issue 19, pp 3551-3560.

[5] Qiang Y, Yuan-wei P, \& Li C (2015). Mechanism of Valley Deformation of High Arch Dam and Effective Stress Principle for Unsaturated Fractured Rock Mass. Chinese Journal of Rock Mechanics and Engineering, Volume 34, Issue 11, pp 2258-2269.

[6] You-zhi L, Guo-xin Z, \& Heng C (2014). Cause Analysis of Valley Shrinkage of Super High Arch Dam and Its Influence on Dam Deformation and Stress. Proceedings of the Annual Meeting of Chinese National Committee on Large Dams in 2014, pp 65-74. 